\title{
Green Synthesis of Copper-Chitosan Nanoparticles and Study of its Antibacterial Activity
}

Appu Manikandan and Muthukrishnan Sathiyabama*

Department of Plant Science, Bharathidasan University, Tiruchirappalli, Tamil Nadu, India

\begin{abstract}
Copper nanoparticle (Cu-NP) synthesis has been gaining attention due to its property and applicability. The main objective of the work is to synthesize stable Cu-NP through green synthesis. This work demonstrates the synthesis of $\mathrm{Cu}-\mathrm{NP}$ by the addition of the acidic chitosan solution to $\mathrm{CuSO}_{4}$ solution with constant stirring at $70^{\circ} \mathrm{C}$ for $12 \mathrm{~h}$. The addition of chitosan aids the stable formation of nanoparticle. The formation of nanoparticle was observed by the peak at $536 \mathrm{~nm}$ using UV-Vis spectroscopy. The interaction between the chitosan and the synthesized nanoparticles was studied using FTIR spectroscopy. The average size of the nanoparticle as determined by zetasizer was about $88.21 \mathrm{~nm}$, while the zeta potential was $-29.0 \mathrm{mV}$. Transmission electron microscopy (TEM) analysis indicated the spherical size with a size ranging between 20-30 $\mathrm{nm}$. The Energy-dispersive X-ray spectroscopy (EDS) analysis showed a homogenous copper-rich composition of metal nanoparticles. The X-ray diffraction (XRD) analysis confirmed the presence of copper nanoparticle with crystalline nature. The synthesised Cu-chitosan nanoparticle exhibited antibacterial activity against gram negative as well as gram positive bacteria. However, the activity was more against gram negative bacteria which may be due to the difference in cell wall composition.
\end{abstract}

Keywords: Cu-Chitosan nanoparticle; TEM; Antibacterial activity

\section{Introduction}

Metal NPs have attracted considerable attention as an antimicrobial agent due to their high surface area to volume ratio, which allows NPs to be effective in very small amounts [1]. An increasing interest in Cu-NPs arises from the useful properties of this metal (thermal and electrical conductivity), which is achieved at much lower cost compared to other noble metals like silver and gold [2]. $\mathrm{Cu}$ is known to have antibacterial and antifungal properties [3,4] also it is non-toxic to mammals [5]. These properties thus make $\mathrm{Cu}-\mathrm{NP}$ synthesis an attractive area.

A number of methods for producing $\mathrm{Cu}-\mathrm{NPs}$ have been developed using both physical and chemical approaches, which involves elevated temperatures, inert atmospheres, large amount of surfactants and organic solvents [6-10]. However, the major limitations in the synthesis of CuNPs are their ease of oxidation [11] to $\mathrm{CuO}$ or $\mathrm{Cu}_{2} \mathrm{O}$ during preparation and storage [12]. Therefore, alternative methods have been developed to synthesize CuNP in the presence of polymers and surfactants as stabilizer $[11,13]$. There are some recent reports on a successful synthesis of $\mathrm{Cu}-\mathrm{NPs}$ in aqueous solution, using chitosan which involve additional reducing and stabilizing agents at various steps [14-18] that are associated with environmental toxicity [19]. Thus, there is still a need for the development of a method for synthesis of stable $\mathrm{Cu}-\mathrm{NPs}$, without involving much co-reducing/ stabilizing agents for antimicrobial application.

This work is an attempt to propose a novel one step green synthesis of $\mathrm{Cu}-\mathrm{NPs}$ with colloidal stability in aqueous media using chitosan, a biopolymer as a reducing and capping agent. The synthesis of Ag-NPs using chitosan as both a reducing and capping agent has been reported [20]. The choice of Chitosan as a stabilizer of the $\mathrm{Cu}-\mathrm{NPs}$ is because of its ability to chelate metals, which makes a perfect material for metal NP synthesis [21]. Synthesis of NPs using polymer has been promising due to their ease of processing, solubility, biocompatibility, less toxicity and also because of the possibility of controlling the growth of the resulting NPs. Travan et al. [22] demonstrated that hydrophilic side chains of chitosan play a fundamental role in stabilization and dispersion of NPs, preventing their agglomeration.
Chitosan can co-ordinate metal ions (eg. Cu ions) before reduction. When $\mathrm{Cu}$ salts dissolve in acidified Chitosan solution, $\mathrm{Cu}$ ion binds to the polymer chains via amino groups. The reduction of these ions takes place further, coupled with the oxidation of the hydroxyl groups [23,24]. Thus NPs generated are strongly attached to the chitosan due to the chemical bond between the electron rich nitrogen present in the amino groups of the polymer and copper $[25,26]$. The use of biopolymer as capping and or reducing agents represents an environmentally friendly alternative to hazardous organic solvents [27].

In the present study, we report the environmentally friendly synthesis of stable $\mathrm{Cu}$ chitosan NPs through green route with chitosan as a stabilizer and or reducing agent. The synthesized NPs were characterized by spectrometry, zetasizer, TEM, XRD and EDS. Their antimicrobial properties were tested using gram negative and gram positive bacteria.

\section{Materials and Methods \\ Synthesis of Cu-Chitosan NPs}

In a typical one-step synthesis protocol $50 \mathrm{ml}$ of $0.75 \%(\mathrm{w} / \mathrm{v})$ chitosan solution was prepared using $0.1 \%$ acetic acid (in distilled water) solution and $25 \mathrm{ml}$ of $50 \mathrm{mM} \mathrm{CuSo}_{4} \cdot 5 \mathrm{H}_{2} \mathrm{O}$ was then added to it and stirred on magnetic stirrer at $70^{\circ} \mathrm{C}$ for $12 \mathrm{~h}$ till the reaction was completed. After $12 \mathrm{~h}$ the colloid was centrifuged at 10,000 $\mathrm{G}$ for 10 mins to separate particles from suspension. The precipitate was re-

*Corresponding author: Muthukrishnan Sathiyabama, Department of Plant Science, Bharathidasan University, Tiruchirappalli, Tamil Nadu, India, E-mail: sathiyabamam@yahoo.com

Received October 21, 2014; Accepted December 06, 2014; Published January 01,2015

Citation: Manikandan A, Sathiyabama M (2015) Green Synthesis of CopperChitosan Nanoparticles and Study of its Antibacterial Activity. J Nanomed Nanotechnol 6: 251. doi: 10.4172/2157-7439.1000251

Copyright: ( 2015 Manikandan A, et al. This is an open-access article distributed under the terms of the Creative Commons Attribution License, which permits unrestricted use, distribution, and reproduction in any medium, provided the original author and source are credited. 
suspended in acetone $(90 \%, \mathrm{v} / \mathrm{v})$ and the centrifugation was repeated three times to remove unreacted reagents. Finally, the precipitate was dissolved in water, dried under vacuum overnight and stored.

\section{Characterization of $\mathrm{Cu}$-Chitosan NPs}

UV-visible spectra were recorded using a Shimadzu UV-Vis1800 Spectrophotometer for the confirmation of NP formation. The structural features of $\mathrm{Cu}$-Chitosan NPs were performed in a Nicolet 560 FTIR spectrometer in a range from 400 to $4000 \mathrm{~cm}^{-1}$ using a $\mathrm{KBr}$ pellet technique. Particle size analysis was performed by dynamic light scattering (DLS). The charge on the surface of the particles was characterized by measuring the zeta potential of the suspension using a Zetasizer (Malvern Instruments, UK). The size and morphology of the Cu-Chitosan NPs were examined by HRTEM (JEOL model 1200 EX). EDS (Energy- dispersive X-ray spectroscopy, Bruker) was applied to study the purity and chemical composition of the samples. X-ray diffraction studies were performed with an X-ray diffractometer (Rigaku Ultima III XRD) with $\mathrm{Cu} \mathrm{Ka} 1$ radiation to determine the structure of a sample. The X-ray source was operated at $40 \mathrm{kV}$ and 40 $\mathrm{mA}$. Diffraction intensity was measured in the reflection mode at a scanning rate of $2^{\circ} / \mathrm{min}$ for $2 \theta=10-70^{\circ}$.

\section{Determination of antimicrobial activity}

A disk diffusion method was used to assay the antibacterial activity of synthesized $\mathrm{Cu}$-Chitosan NPs $(50 \mu \mathrm{g} / \mathrm{ml})$, against test strains in Muller-Hinton agar media. For control experiments, ampicillin and streptomycin were used for gram negative (E.coli, Salmonella paratyphi) and gram positive bacteria (Bacillus) respectively. Chitosan was also used separately to check the antibacterial activity. The plates were incubated for $24 \mathrm{~h}$ at $37^{\circ} \mathrm{C}$ and inhibition zones were measured.

\section{Results and Discussion}

The chemical reduction of metal salt is one of the most convenient and promising synthetic approaches to obtain metallic nanoparticles with relatively inexpensive setups. $\mathrm{Cu}-\mathrm{NPs}$ are very difficult to obtain by simple reduction of copper salts in aqueous solution, when compared with other metals such as Ag, $\mathrm{Au}$ or $\mathrm{Pt}$, since copper oxidizes to $\mathrm{CuO}$ and $\mathrm{Cu}_{2} \mathrm{O}[25,28,29]$. However, the size controlled synthesis of $\mathrm{Cu}-\mathrm{NPs}$ can be obtained by using a carrier material, such as a polymer matrix e.g., chitosan which is having a superior copper binding properties $[17,29]$. This polymer has been applied as a reducing agent and or a stabilizing agent in the formation of $\mathrm{Cu}-\mathrm{NPs}$, which inhibits agglomeration, minimizes oxidation reaction thus limits the particle growth.

The evolution of the absorption spectra of different aliquots overtime of a solution containing copper sulphate $(50 \mathrm{mM})$ in chitosan $(0.75 \% \mathrm{w} / \mathrm{v})$ showed major peak around $500-600 \mathrm{~nm}$ (data not shown), thus revealing the formation of $\mathrm{Cu}-\mathrm{NPs}$. The colloidal $\mathrm{Cu}-\mathrm{NPs}$ prepared at $12 \mathrm{~h}$ at $70^{\circ} \mathrm{C}$ showed a characteristic single absorption peak at $536 \mathrm{~nm}$ (Figure 1), which indicates the reduction of $\mathrm{Cu}^{2+}$ ions in the presence of chitosan to highly monodisperse NPs. There are many reports on the blue shift of the surface plasmon resonance (SPR) of the metallic NPs with their decreasing size [30]. Nanosized $\mathrm{Cu}$ particles generally exhibit an SPR at around 500-600 $\mathrm{nm}$ [31]. When copper sulphate was added to the chitosan solution, $\mathrm{Cu}^{2+}$ ions would attach to chitosan macromolecules by electrostatic interactions. The electron-rich oxygen atoms of polar hydroxyl and ether groups of chitosan are likely to interact with electropositive metal cations [17]. It has been reported that chitosan acts as a controller of nucleation as well as a stabilizer [32].

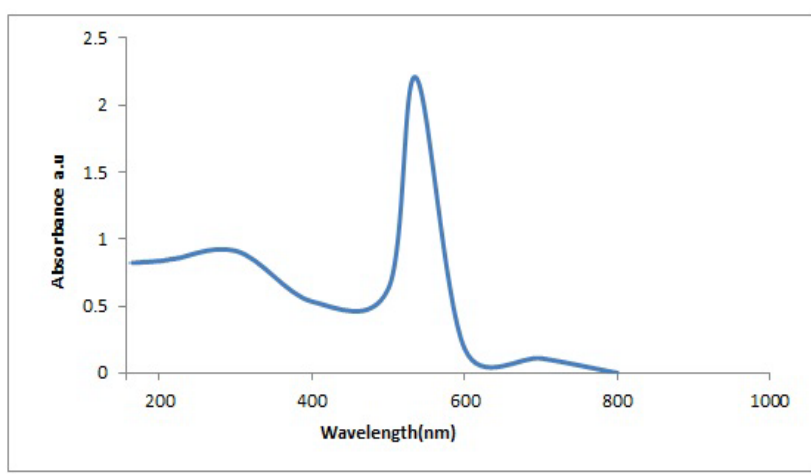

Figure 1: UV- visible spectrum of synthesized copper-chitosan nanoparticle.

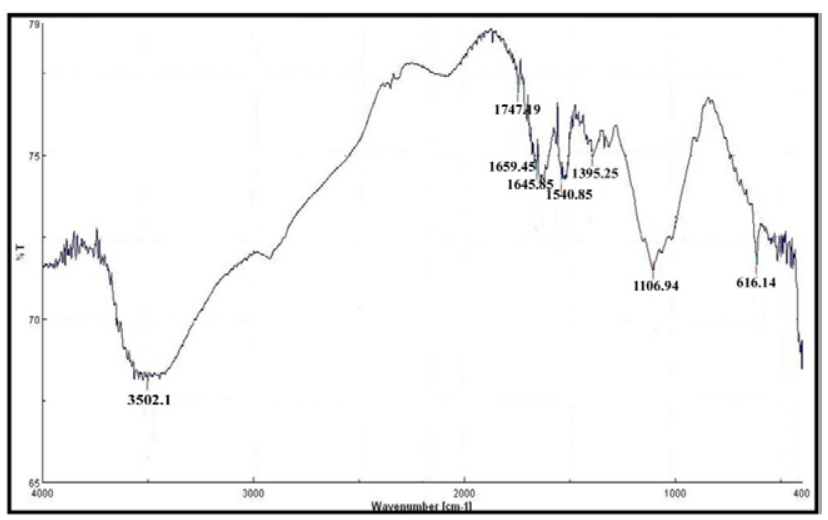

Figure 2: FT-IR spectra of Cu-Chitosan nanoparticle.

FTIR analysis was conducted to determine the molecular interactions between chitosan and the synthesized NPs. FTIR analysis shows the presence of bands at $3502.1 \mathrm{~cm}^{-1}$ (due to overlap of $\mathrm{O}-\mathrm{H}$ and $\mathrm{N}-\mathrm{H}$ stretching), $1747.19 \mathrm{~cm}^{-1}$ (C=O stretching), $1659.45,1645.85$ and $1540.85 \mathrm{~cm}^{-1}$ (NH $\mathrm{NH}_{2}$ bending), $1395.25 \mathrm{~cm}^{-1}$ (C-H bending), 1106.94 $\mathrm{cm}^{-1}$ (C-O-C stretching) $616.14 \mathrm{~cm}^{-1}$ (Figure 2). The peak at 616.14 $\mathrm{cm}^{-1}$ evidence the interaction between $\mathrm{Cu}-\mathrm{NPs}$ and chitosan, which indicates that NPs were capped by the polymer $[12,13]$.

The experiments described above indicate the importance of chitosan in the performed synthesis. Chitosan, as a biopolymer, has a significant content of primary amines and hydroxyl groups and possess a strong affinity towards metal ions, which are incorporated by simple chelation by ion exchange, thereby making it an excellent support for nucleation of $\mathrm{Cu}$-NPs. The generation of $\mathrm{Cu}^{2+}$ Chitosan complexes in solution enables metal ion reduction. From these results, it can be envisaged that the biopolymer plays an important role as polymeric capping agent (Stabilizer). There are reports that chitosan plays a more specific role as a stabilizing agent [25].

The average size of $\mathrm{Cu}$-chitosan NP measured by zetasizer was $88.21 \mathrm{~nm}$ (Figure 3a) with a narrow size distribution (PDI-0.45). Zeta potential is an important parameter for determining the stability of nanoparticle suspensions. For a physically stable NP suspension to be stabilized solely by electrostatic repulsion, a zeta potential of $\pm 30 \mathrm{mV}$ is required as a minimum [31]. The mutual repulsion of NPs depends on having either a large negative or positive zeta potential. Zeta potential measurements of $\mathrm{Cu}$-Chitosan NPs are presented in (Figure $3 \mathrm{~b}$ ) which 

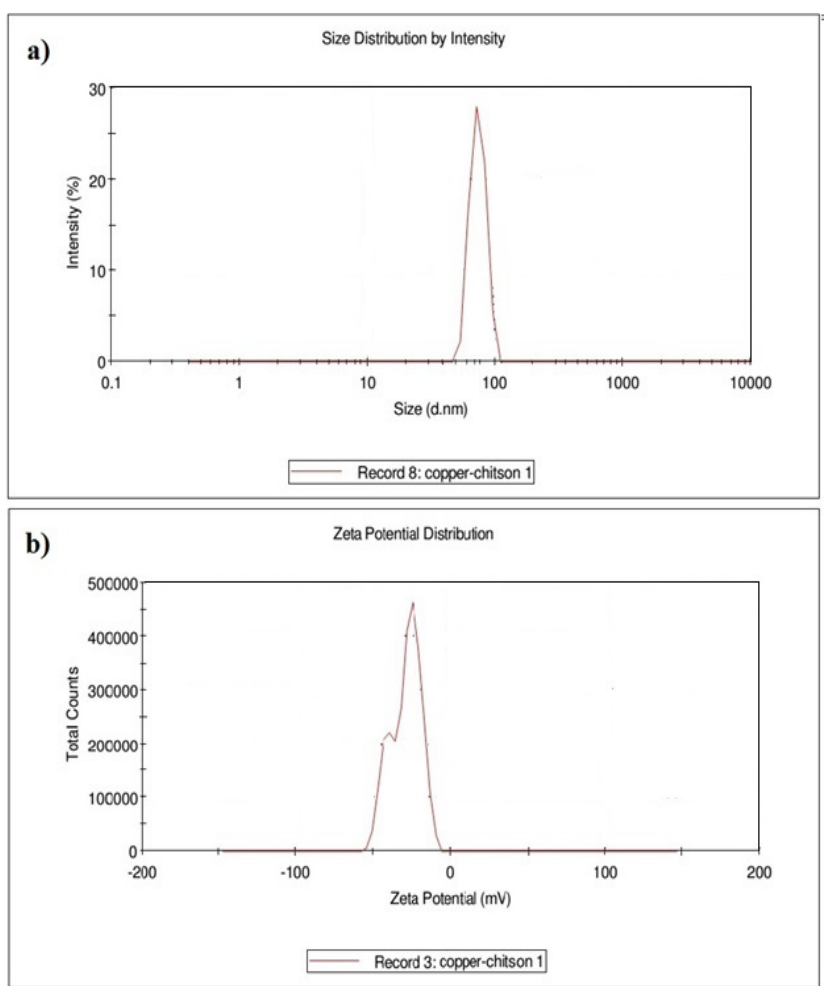

Figure 3: Dynamic light scattering (a) and zeta-potential of Cu-Chitosan nanoparticle (b).

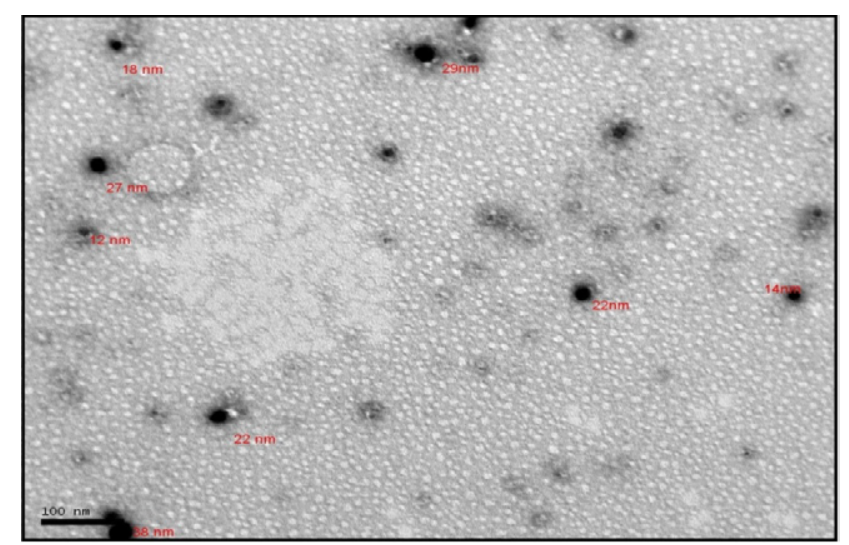

Figure 4: HRTEM micrograph of synthesized copper-Chitosan nanoparticle. Scale bar $=100 \mathrm{~nm}$.

shows that the synthesized NPs have a negative surface charge $(-29.0$ $\mathrm{mV}$ ). This implies the colloidal stability of the nanoparticles. Chitosan can form various chemical bonds with metal components, thus enhancing the stability of the NPs [32] and prevents agglomeration.

Figure 4 shows a high-resolution electron microscope (HRTEM) micrograph of $\mathrm{Cu}-\mathrm{NPs}$ which are spherical in shape and size range of about 20-30 nm. Further, TEM images of the sample corroborated the stability of the NPs in the presence of chitosan as there was no agglomeration and oxidation (Figure 4). The size difference between TEM and DLS analyses may be due to different principle involved in these two techniques. The DLS measurement involves hydrodynamic state of nanoparticle where as it is a dry state in TEM measurement
$[33,34]$. EDS analysis showed a very homogenous copper-rich composition for metal NPs (Figure 5). The weak carbon and oxygen signals may be due to chitosan that surrounds the Cu-NPs $[25,35]$. $\mathrm{X}$-ray diffraction patterns for the $\mathrm{Cu}$-Chitosan nanoparticles, was shown in The diffraction angles at $43.02^{\circ}, 50.62^{\circ}$, which correspond to the characteristic face centered cubic ( $\mathrm{fcc}$ ) of copper lines indexed at (111), (200), respectively [36] indicates the crystalline nature. The diffraction angle observed at 20.54 is related to the chitosan [37] present in the nanoparticle. Further the presence $\mathrm{CuO}$ or $\mathrm{Cu}_{2} \mathrm{O}$ was not detected in the diffraction.

\section{Antimicrobial activity}

The Chitosan stabilized Cu-NPs exhibited inhibitory activity towards gram negative, positive bacteria (Figure 7a). However, more antibacterial activity was observed against gram negative bacteria (Figure7b). This may be due to the differences in the bacterial cell wall structure of gram negative (single peptidoglycan layer) to the gram positive organism (several peptidoglycan layers). The adhesion of NPs to the surface of a bacterium alters its membrane properties ultimately causing death [38]. The results of the present study are in agreement with other reports that indicate greater activity in copper NP against gram negative microorganism [39]. Further chitosan demonstrated only negligible zone of inhibition against test bacteria (data not shown) suggesting a lack of antimicrobial activity of chitosan at $\mathrm{pH} 7.4$, which

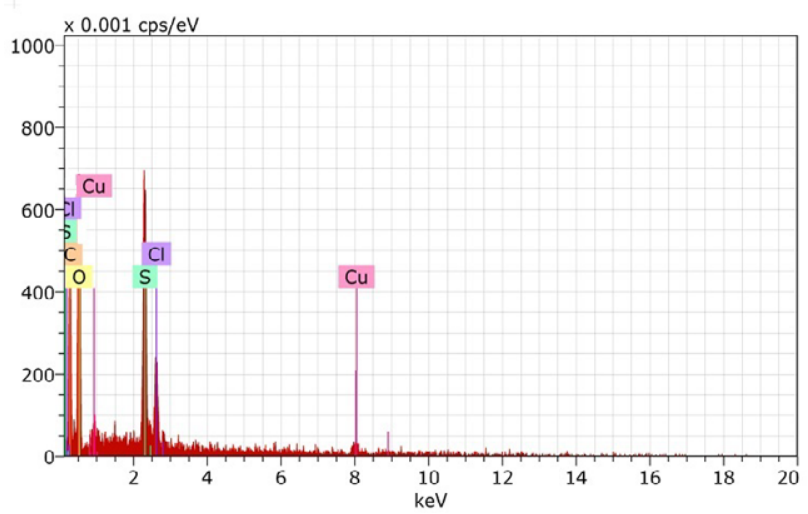

Figure 5: Energy-dispersive spectroscopy spectrum of Cu-Chitosan nanoparticle. Various X-ray emission peaks are labelled.

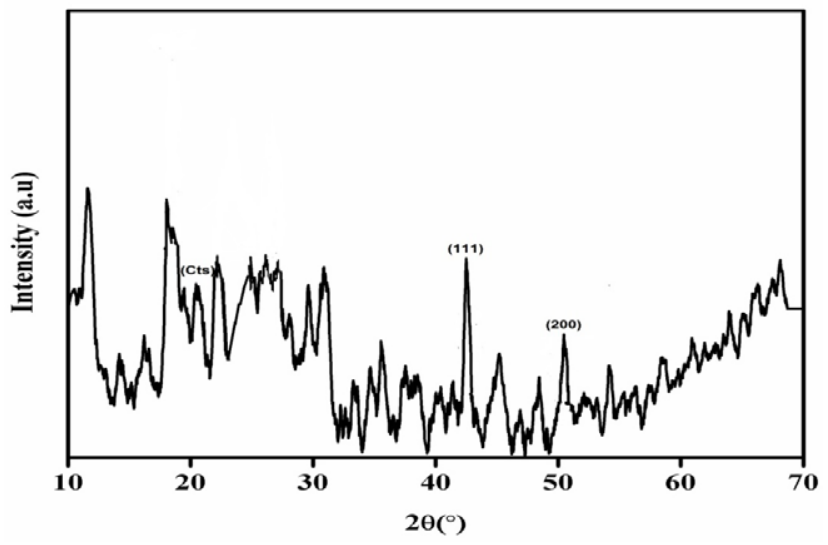

Figure 6: X-ray diffraction patterns of synthesized copper-Chitosan nanoparticles. 


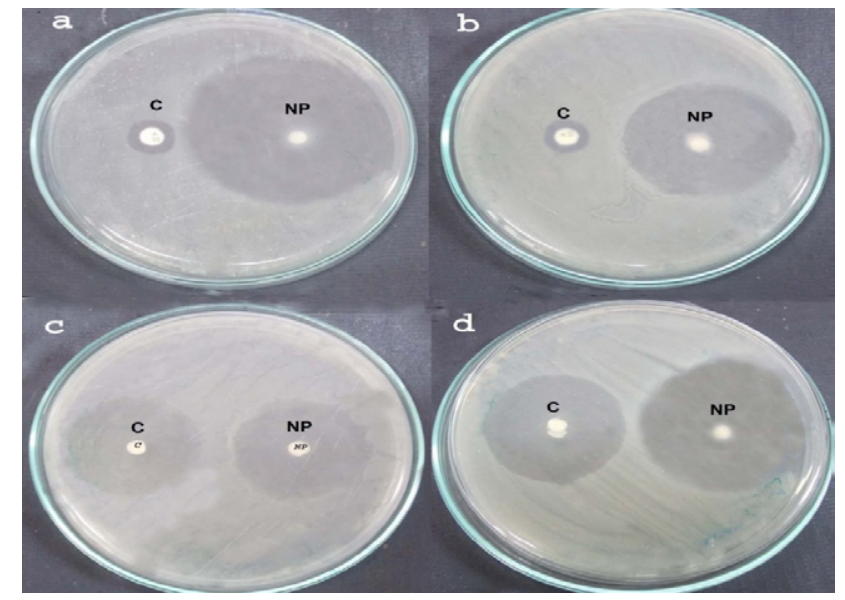

Figure 7a: Antimicrobial activity of Cu-Chitosan nanoparticle against gram negative and gram positive bacteria by disk diffusion method. a) E.coli, b) Salmonella, c) Staphylococcus aureus, d) Bacillus.

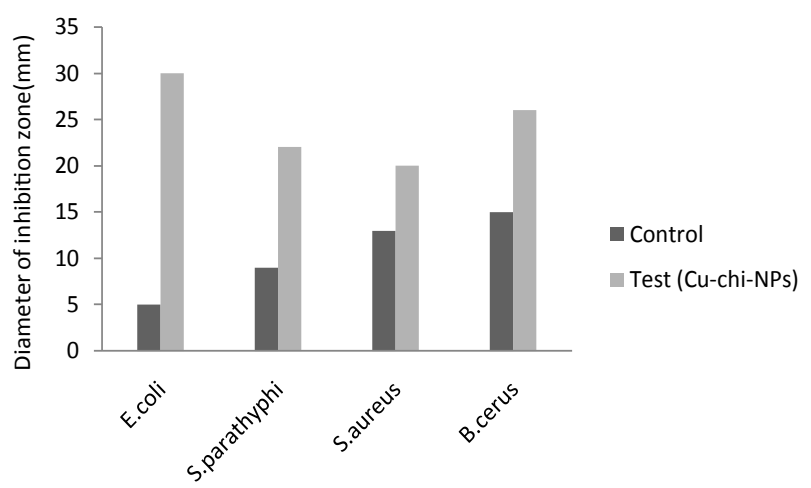

Figure 7b: Effect of Cu-Chitosan nanoparticle on inhibition (in $\mathrm{mm}$ ) of growth of gram negative and gram positive bacteria on Muller- Hinton Agar plate.

is the $\mathrm{pH}$ of the Muller-Hinton agar. This is in accord with the fact that chitosan has antimicrobial activity only in an acidic medium due to its poor solubility above $\mathrm{pH} 6.5$ [40].

\section{Conclusion}

Colloidal stable $\mathrm{Cu}$-chitosan NPs with a size range of 20-30 $\mathrm{nm}$ have been successfully synthesized through green synthesis in the presence of a biopolymer, chitosan. The synthesized NPs were characterized by UV-Vis, FTIR, TEM, EDS and XRD analyses. The main role attributable to the Chitosan is related to its chelating capacity. The present singlestep synthetic method represents a simple, convenient, cost-effective and eco-friendly alternate to other synthetic methods. Our results indicate the potential of copper NPs for combating pathogenic microorganisms. This may be suitable for formulation of new types of antimicrobial materials for pharmaceutical and biomedical application. However, further in vivo studies to determine the toxicity of these NPs are necessary.

\section{Acknowledgement}

The authors thank the University authorities for providing facilities. Bharathidasan University for providing University Research Fellowship.

\section{References}

1. Sundaresan K, Sivakumar A, Vigneswaran C, Ramachandran T (2012) Influence of nano titanium dioxide finish, prepared by sol-gel technique, on the ultraviolet protection, antimicrobial, and self-cleaning characteristics of cotton fabrics. J Indust Text 41: 259-277.

2. Han WK, Choi JW, Hwang GH, Hong SJ, Lee JS, et al. (2006) Fabrication of $\mathrm{Cu}$ nano particles by direct electrochemical reduction from $\mathrm{CuO}$ nano particles. Appl Surface Sci 252: 2832-2838.

3. Hsiao SH, Fang TH, Hwang JS (2006) The bioconcentration of trace metals in dominant copepod species off the northern Taiwan coast. Crustaceana 79: 459-474.

4. lakovidis I, Delimaris I, Piperakis SM (2011) Copper and Its Complexes in Medicine: A Biochemical Approach. Mol Bio Int.

5. Fleming CA, Trevors JT (1989) Copper toxicity and chemistry Indeed, in the environment: A review. Water Air Soil Pollut 44: 143-158.

6. Arul DN, Paul RC, Gedanken A (1998) Synthesis, characterization, and properties of metallic copper nanoparticles. Chem Mater 10: 1446-1452.

7. Joshi S, Patil S, Iyer V, Mahumuni S (1998) Radiation induced synthesis and characterization of copper nanoparticles. Nanostruct Mater 10: 1135-1144.

8. Cheng X, Zhang X, Yin H, Wang A, Xu Y, et al. (2006) Modifier effects on chemical reduction synthesis of nanostructured copper. Appl Surf Sci 253: 2727-2732.

9. El-Nour KM, Eftaiha A, Al-Warthan A, Ammar RA (2010) Synthesis and applications of silver nanoparticles. J Chemist 3: 135-140.

10. Thakkar KN, Mhatre SS, Parikh RY (2010) Biological synthesis of metallic nanoparticles. Nanomed Nanotech Bio Med 6: 257-262.

11. Wu SH, Chen DH (2004) Synthesis of high-concentration Cu nanoparticles in aqueous CTAB solutions. J Colloid Interface Sci 273: 165-169.

12. Usman MS, ezzat el M, Shameli ZK, Salama NZ, Ibrahim NA, et al (2013) Synthesis, characterization, and antimicrobial properties of copper nanoparticles. I J Nanomed 17: 4467-4479.

13. Dang TM, Le TT, Fribourg-Blanc E, Dang MC (2011) The influence of solvents and surfactants on the preparation of copper nanoparticles by a chemical reduction method. Adv Nat Sci Nanosci Nanotechnol 2.

14. Wu C, Mosher BP, Zeng T (2006) One-step green route to narrowly dispersed copper nanocrystals. J Nanopart 8: 965-969.

15. Xiong J, Wang $Y$, Xue Q, Wu X (2011) Synthesis of highly stable dispersions of nanosized copper particles using L-ascorbic acid. Green Chem 13: 900-904.

16. Saharan V, Mehrotra A, Khatik R, Rawal P, Sharma SS, et al. (2013) Synthesis of chitosan based nanoparticles and their in vitro evolution against phytopathogenic fungi. I J Biol Macromol 62: 677-683.

17. Zain NM, Stapley AG, Shama G (2014) Green synthesis of silver and copper nanoparticles using ascorbic acid and chitosan for antimicrobial applications. Carbohydr Polym 112: 195-202.

18. Tokarek TW, Huo JA, Odame-Ankrah CA, Hammoud D, Taha YM, et al. (2014) A gas chromatograph for quantification of peroxycarboxylic nitric anhydrides calibrated by thermal dissociation cavity ring-down spectroscopy. Meas Tech Discuss 7: 5953-6019.

19. Lim S, Hudson SM (2004) Synthesis and antimicrobial activity of a water soluble chitosan derivative with a fiber reactive group. Carbohydr Resear 339: 313-319.

20. Sanpui P, Murugadoss A, Durgaprasad PV, Ghosh SS, Chattopadhyay A, et al. (2008) The antibacterial properties of a novel chitosan-Ag-nanoparticle composite. Int J Food Microbiol 124: 142-146.

21. Hardy JJ, Hubert S, Macquarrie DJ, Wilson AJ (2004) Chitosan-based heterogeneous catalysts for suzuki and heck reactions. Green Chem 6: 53-56.

22. Travan A, Pelillo C, Donati I, Marsich E, Benincasa M, et al. (2009) Non-cytotoxic Silver Nanoparticle-Polysaccharide Nanocomposites with Antimicrobial Activity. Biomacromolecules 10: 1429-35.

23. Tran HV, Tran LD, Ba CD, Vu HD, Nguyen TN, et al. (2010) Synthesis, characterization, antibacterial and antiproliferative activities of monodisperse chitosan-based silver nanoparticles. Colloids Surf .A 360: 32-40 
Citation: Manikandan A, Sathiyabama M (2015) Green Synthesis of Copper-Chitosan Nanoparticles and Study of its Antibacterial Activity. J Nanomed Nanotechnol 6: 251. doi: 10.4172/2157-7439.1000251

24. Wei D , Qian W (2008) Facile synthesis of Ag and Au nanoparticles utilizing chitosan as a mediator agent. Colloids Surf B. 62: 136-42

25. Tokarek K, Hueso JL, Kustrowski P, Stochel G (2013) Green Synthesis of Chitosan-Stabilized Copper Nanoparticles. E J Inor Che 28: 4940-4947.

26. Regiel A, Irusta S, Kyziol A, Arruebo M, Santamaria (2013) Preparation and characterization of chitosan - silver nanocomposite films and their antibacterial activity against Staphylococcus aureus. Nanotechnology doi: 10.1088/09574484/24/1//015101.

27. Pakiari AH, Jamshidi Z (2007) Interaction of amino acids with gold and silver clusters. J. Phys. Chem. A. 111: 4391-6

28. Mallick S, Sharma S, Banerjee M, Ghosh SS, Chattopadhyay A, et al. (2012) lodine-Stabilized Cu Nanoparticle Chitosan Composite for Antibacteria Applications. ACS Appl Mater Interfaces 4: 1313-1323.

29. Mallick K, Witcomb MJ, Scurrell MS (2006) In situ synthesis of copper nanoparticles and poly (o-toluidine): a metal-polymer composite material. Eur Polym J 42: 670-675.

30. Huang H, Yuan Q, Yang X (2004) Preparation and characterization of metalchitosan nanocomposites. Colloids and Surfaces B: Biointerfaces 39: 31-37.

31. Singare DS, Marella S, Gowthamrajan K, Kulkarni GT, Vooturi R, et al. (2010) Optimization of formulation and process variable of nanosuspension: An industrial perspective. Int J Pharma 402: 213-220.

32. Muzzarelli RA (2011) Potential of chitin/chitosan-bearingmaterials foruranium recovery: An interdisciplinary review. Carbohydr Polym 84: 54-63.
33. Wu Y, Yang W, Wang C, Hu J, Fu S, et al.(2005) Chitosan nanoparticles as a novel delivery system for ammonium glycyrrhizinate. Int J Pharm 295: 235-245.

34. Khlebtsov BN, Khlebtsov NG (2011) On the Measurement of Gold Nanoparticle Sizes by the Dynamic Light Scattering Method. Colloid Journal 73: 118-127.

35. Jayaseelan C, Ramkumar R, Rahuman AA, Perumal P (2013) Green synthesis of gold nanoparticles using seed aqueous extract of Abelmoschus esculentus and its antifungal activity. Indust. Crops Produc 45: 423-429.

36. Mott D, Galkowski J, Wang LY, Luo J, Zhong CJ, et al.(2007) Synthesis of sizecontrolled and shaped copper nanoparticles. Langmuir 23: 5740-5745.

37. Ahmad MB, Lim JJ, Tay MY, Shameli K, Ibrahim NA, et al. (2011) Synthesis of silver nanoparticles in chitosan, gelatin and chitosan/gelatin bionanocomposites by a chemical reducing agent and their characterizations. Molecules 16: 7237 7248.

38. Li Q, Mahendra S, Lyon DY, Brunet L, Liga M, et al. (2008) Antimicrobial nanomaterials for water disinfection and microbial control: Potential applications and implications. Water Research 42: 4591-4602.

39. Longano D, Ditaranto N, Sabbatini L, Torsi L, Cioffi N, etal. (2012) NanoAntimicro Progress and Prospects 3: 85-117.

40. Rabea El, Badawy ME, Stevens CV, Smagghe G, Steurbaut W, et al.(2003) Chitosan as antimicrobial agent: applications and mode of action. Biomacromolecule 4: 1457-1465. 